\title{
Cusseque - Para-ecologist Miguel Sachilula Hilario
}

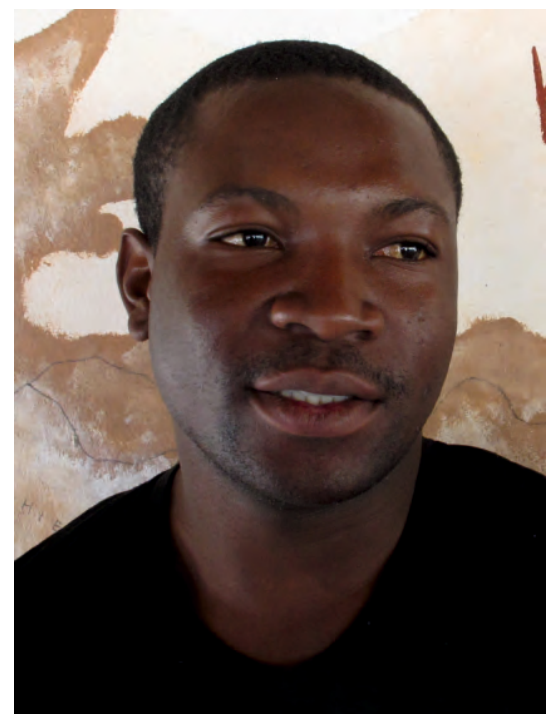

Fig. 1: Miguel Sachilula Hilario (photo: V. S. Mtuleni).

My name is Miguel Sachilula Hilario (Fig. 1). I was born in the Bie Province of Angola and I grew up in the Chitembo, Kuquema, and Cuito areas as well as in Luanda. I also lived in the Mungo Province of Zambia for 10 years during the war in Angola. I speak the following eight languages: Portuguese, English, Umbundu, Nhanja, Mbunda, Nganguela, Chinhanja and Chilozi. Before I became a para-ecologist, I worked for various organizations, collecting a broad range of experiences:

- From 2006 to 2007 I was teaching English in grade five and six in Zambia and in grade seven to nine in Angola. In Zambia I taught at the Nangweshi Secondary
School in a Refugee Camp and in Luanda I taught at a private secondary school called DEVIR.

- From 2008 to 2009 I worked as a Community Development officer in Zambia, employed by the UN through the Ministry of Community Development and Social Services (MCDSS).

- From 2009 to 2010 I was a translator from Portuguese to English, Umbundu, Nhanja, Chilolzi, Mbunda, Nganguela and Chilozi, being employed by the UN through an NGO called CORD (a Christian development organization for refugees)

- Besides that, I was the head coach of the Benfica Football Club at the Mayukwayukwa Refugee Camp in Zambia from 2007 until I left Zambia in 2010.

Through these activities, I gained a number of experiences, which are among others, good teaching skills and methodologies, experiences in how to interact with communities at differen levels (Fig. 2), and how to help the vulnerable people by looking for alternative solutions for their problems. Through the interaction with people of different backgrounds, I also gained skills in being a good translator and got more knowledge of how to coach football.

As a TFO para-ecologist I am the chief organizer of almost everything for the TFO project at the Cusseque core site. I help with

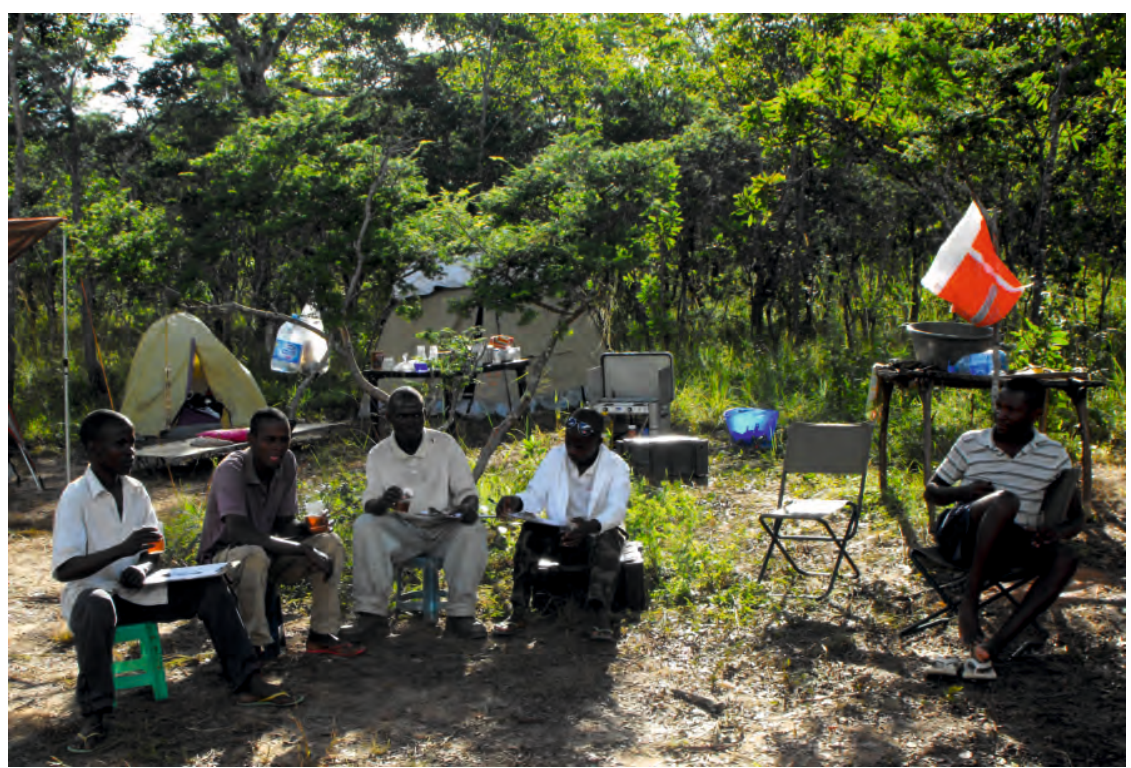

translations and facilitate the communication between the researchers, stakeholders and members of the local communities that live in the study area. I organize workshops and accommodation for researchers. I sometimes camp with the researchers at the core site. I assist the researchers on the site with their work and I continue carrying out field work in their absence, e.g. by doing the yield assessment (Fig. 3).

Through my work in the TFO project I started to understand the project's objectives and I learnt how to communicate professionally with stakeholders, researchers and the local communities. I also learnt how to use different computer programs, the use of GPS devices, how to download data from the yellow tiny tag data loggers that measure humidity and temperature, how to assess the farmers yield, knowing different types of soil and how to assess the biomass of bushes and trees.

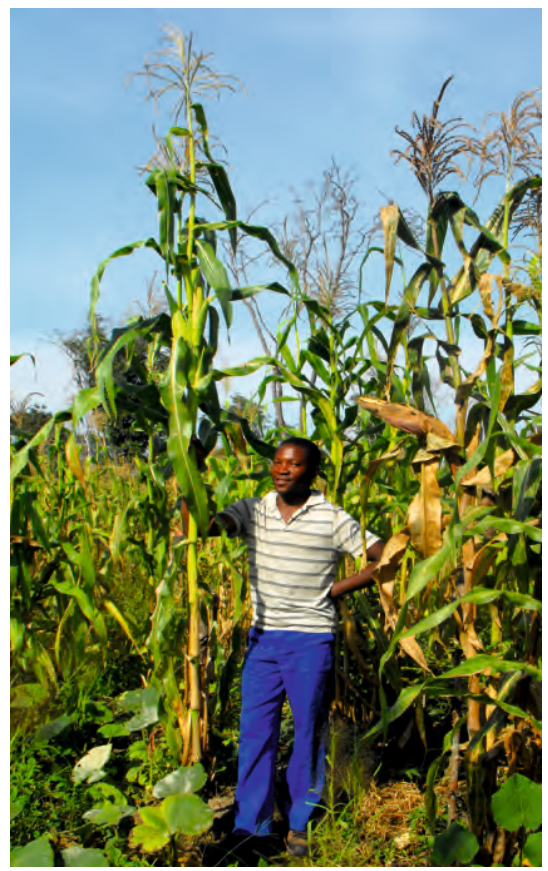

Fig. 3: Miguel Hilario in a maize field during yield assessment in Cusseque (photo: B. Kowalski).

Fig. 2: Miguel at focus group discussion in Cusseque (photo: B. Kowalski). 


\section{Acknowledgements}

The project was funded by the BMBF (The Future Okavango project). For details see authors' general acknowledgements in this volume. 